\title{
Do cuidado de si para a vida potyguara como produção de saúde
}

\section{Del cuidado de si para la vida potyguara como producción de salud}

\author{
Maria Lidiany Tributino de Sousa \\ Universidade Estadual do Ceará \\ e-mail: tribudiany@gmail.com \\ Andrea Caprara \\ Universidade Estadual do Ceará \\ e-mail: andreacaprara1@gmail.com
}

DOI: 10.26512/interethnica.v22i1.25472

Resumo: O conceito saúde indígena, na literatura acadêmica e serviços de saúde, apresenta-se empobrecido de questões que dizem respeito à vida nas aldeias indígenas. Ao longo do trabalho de campo/trabalho de mato e dos encontros com as lideranças indígenas, surgiram indícios que apontaram o adoecimento dessa expressão saúde indígena na literatura acadêmica. Esse escrito analítico procura articular as discussões entre o Cuidado de Si presente no livro Hermenêutica do Sujeito de Foucault e os modos de cuidado em saúde nas aldeias indígenas dos Potyguara que possibilitaram pensar a saúde e o cuidado indígena como modos de produção de vida que são capazes de operar deslocamentos na saúde, no cuidado e na clínica na área da Saúde Coletiva.

Palavras-chave: saúde indígena, etnomedicina, indigenismo.

Introdução: o surgimento do problema

Na Saúde Coletiva, no âmbito dos artigos publicados sobre saúde indígena, são reduzidas as pesquisas sobre essa temática, principalmente, no que tange ao Nordeste brasileiro e ao Ceará. De acordo com o IBGE (2016), o estado do Ceará tem uma população estimada em 8.963 .663 pessoas. Desse montante, a população indígena foi avaliada em 32.434, ou seja, o,36\% da população total, sendo 14 as etnias indígenas.

Segundo o mesmo censo, o município cearense de Monsenhor Tabosa apresenta uma proporção de $11,6 \%$ dos indígenas em relação aos demais munícipes taboenses. Embora Fortaleza concentre a maioria da população indígena, a proporção com os demais fortalezenses é inexpressiva devido à característica populosa da capital cearense.

No Ceará, o povo Potyguara de Monsenhor Tabosa procura estabelecer diferenças com os demais povos Potiguara do Nordeste. Uma delas é pela escrita do nome, substituindo o i por um y. Os Potyguara do Ceará estão presentes em Crateús, Poranga, Boa Viagem, Novo Oriente, Quiterianópolis, Tamboril e Monsenhor Tabosa. 
Em Monsenhor Tabosa, os Potyguara habitam as localidades de Olho Dágua dos Canutos, Mundo Novo, Jacinto, Pau-Ferro, Passarinho, Merejo, Tourão entre outras, juntamente com outras etnias como Tabajara, Gavião e Tubiba-Tapuia.

Em 2015, iniciei uma pesquisa na área da Saúde Coletiva para construção de uma tese com o objetivo cartografar os modos de vida Potyguara em Monsenhor Tabosa, para pensar uma saúde que não fosse para ou dos indígenas, mas uma saúde com os Potyguara, criando deslocamentos no conceito saúde indígenas na área da Saúde Coletiva.

Em 2016, realizei uma pesquisa com o descritor Health of Indigenous Peoples, através da Biblioteca Virtual da Saúde (BVS), que apresentou um total de 1.057 estudos, sendo 804 em bases de dados internacionais e 80 em bases nacionais (58 do Brasil). A revista Cadernos de Saúde Pública possuía a maioria das produções no formato de artigos.

No Brasil, há expoentes no que se refere às pesquisas sobre política de atenção à saúde dos povos indígenas, xamanismo, alcoolização, rituais, gênero, como: Luiza Garnelo e Esther Jean Langdon. Assim como, trabalhos de natureza epidemiológica, interligando saúde indígena e nutrição, educação, habitação e saneamento de autores, como Coimbra Jr e Ricardo Ventura Santos.

Em relação ao Ceará, há duas produções na área da saúde indígena da professora Raquel Rigotto que não estão na BVS, e a maior parte das publicações sobre os indígenas no Ceará são, principalmente, de pesquisadores da Antropologia e História.

Das produções que se referem aos Potyguara temos as contribuições dos antropólogos Estevão Martins Palitot e Carmen Lúcia Silva Lima.

Os estudos na área da saúde expõem que a população indígena ainda vivencia, desde o período colonial, situações de exclusão, marginalidade e discriminação que a coloca em situação de fragilidade frente aos agravos à saúde.

A maioria das produções na área da saúde, que constam nas revistas de maior impacto, revela que a morbidade da população indígena está relacionada a uma alta incidência de doenças infecciosas, crônicas, mas, em menor número, discute as condições que fragilizam o estado de adoecimento, como: precariedade das condições de vida, expropriação, intrusão das terras indígenas.

A temática saúde indígena ainda é fortemente representada pelo discurso biomédico, quer dizer, por um modelo em que as pessoas que necessitam de cuidados acabam sendo assujeitadas à condição de depositárias de doenças e de terapêuticas, sobretudo, centradas nas prescrições dos profissionais de saúde.

Percebeu-se também que, na literatura acadêmica da Saúde Coletiva, a saúde indígena, desde seu entendimento como ausência de doença, bem-estar, até direito humano, exprime que saúde é não ser doente, não estar doente, ou ter acesso a direitos humanos, ou seja, produções de um estado de coisa balizadas pela noção de "unidade", de "uno". 
Depara-se com a expressão saúde indígena sendo apresentada em algumas publicações científicas como um atributo natural, existindo desde sempre nos grupos indígenas, incluindo ideias de algo fixo, subsistente e relacionado à ausência de doenças e ao controle pelos programas de saúde. Uma expressão da qual se parte e um limite para além do qual não se pode ir, e do qual não há a garantia de se obter asserções sobre as condições que este conceito é conjecturado. Dito de outra maneira, percebe-se que o conceito saúde indígena não é problematizado, posto em questão nessas publicações.

A maneira como era apresentada a expressão saúde indígena inquietou-me, e, ao longo do trabalho de campo, entre os anos de 2015 e 2017, para construção da tese, percebi, através das observações participantes e conversas com as lideranças indígenas, pajé, rezadeiras, caciques, profissionais da atenção à saúde indígena, que a saúde indígena Potyguara, na heterogeneidade, problematizava a saúde indígena científica.

Não tive, com a tese, o propósito de marcar as diferenças e semelhanças entre o modelo de saúde formal indígena e a saúde Potyguara, em uma perspectiva dialética, cujo intento fosse produzir sínteses. Procurei vizinhanças na tentativa de problematizar as ontologias e fundamentos presentes no nosso conceito de saúde indígena e em outros conceitos a ele articulados como o de cuidado em saúde.

Em 2015, ao concluir uma disciplina sobre o livro Hermenêutica do Sujeito de Foucault no doutorado em saúde coletiva, perguntei-me: como pensar em modos de cuidado em saúde nas aldeias indígenas dos Potyguara? Como nesse período já começara o trabalho para elaboração da tese, esses encontros entre textos lidos e conversas realizadas, possibilitaram este escrito analítico através do qual buscarei problematizar o nosso conceito de saúde e cuidado a partir das contribuições dos conceitos de "cuidado de si”, Biopolítica e Biopoder em Foucault e das aproximações da produção de vida Potyguara como produção de saúde.

\section{O CUIDADO DE SI EM FOUCAULT}

Nas aulas compiladas no livro Hermenêutica do Sujeito, Foucault (2006) traz um estudo, através de várias obras literárias, das noções Gnôthiseautón e Epiméleiaheautoû. A primeira, traduzida por "conhece-te a ti mesmo", uma prescrição délfica, colocada na história do pensamento ocidental como fórmula fundadora da relação entre sujeito e verdade, enquanto que a segunda, referiase ao "cuidado de si", posta às margens, desconsiderada no "momento cartesiano" e na construção do pensamento filosófico moderno.

As noções Gnôthiseautón e Epiméleiaheautoû foram ramificando-se com outras significações que, antes, não lhes eram atribuídas:

- O "conhece-te a ti mesmo" não trazia uma necessidade de conhecimento de si como fundamento de uma moral, mas, na antiguidade, era uma aplicação concreta do princípio do cuidado de si. 
- A noção "cuidado de si" indicava: atitude consigo, com os outros e com o mundo; conversão do olhar, da atenção, que quer dizer meditação e exercícios. Esta noção aparece como processo de subjetivação para constituição de cidadãos da polis grega.

Nos séculos I e II, denominados de idade do ouro na história do cuidado de si, essa expressão tornou-se um princípio geral e incondicional, imposto a todos e não somente aos futuros governantes da polis grega. Nesse contexto, cuidar de si não era exclusivamente uma preparação para a vida política.

O cuidado de si, antes do cristianismo, não era cuidado de interesse, mas produção ético-político-estético de si mesmo, um movimento para uma estilização da vida, e este "si" não era um sujeito acabado, mas uma obra a realizar-se, uma experiência, uma prática. Assim, cuidar de si era cuidar da prática, a partir de verdades que são preceitos de conduta e que devem ser escutados, lidos, memorizados e vividos.

Para os estóicos, a verdade não está no interior das pessoas, mas nos esquemas indutores de ações (lógoi) dos mestres, e a askêsis não é renúncia, mas prática pela qual se pode transformar a verdade, o conhecimento de si em ação, em cuidado de si. Desse modo, o cuidado de si não se constituía apenas como princípio, mas como uma prática permanente.

Com a teologia, há uma nova relação entre subjetividade e verdade. O princípio é um sujeito cognoscente que encontra em Deus (que tudo conhece) seu modelo. Desse modo, o cuidado de si e o acesso à verdade são vistos como sendo dados pelo conhecimento e não por condições de transformação do sujeito.

No "momento cartesiano", o conhecimento é valorizado, tornando-se a primeira certeza, condição de uma verdade que o sujeito alcança através da razão. No mundo moderno, o "si" é visto como sujeito, representação de um "eu", agência de enunciação, de produção de discursos que são compreendidos como base de operação para decifração de uma verdade interior.

Na aula de 22/02/1978 do curso "Segurança, território, população”, Foucault (2008) discute a constituição típica do sujeito moderno pelo poder pastoral cristão, traduzido como uma relação de obediência estrita e absoluta do monge ao seu superior, através das tecnologias do exame de consciência, que dependia de uma contínua investigação do próprio pensamento e dos próprios desejos, os quais deveriam ser relatados na confissão.

Para o pensamento cristão não há necessidade de se modificar, já que se acessa a verdade por decifrações, pela consciência ou pela exegese de uma verdade no interior dos indivíduos. O cuidado de si passa a ser visto como egoísmo e como desobrigação para com o outro e interesse por si próprio, que deve ser conhecido, corrigido e purificado.

O sujeito é obrigado a saber o que passa no seu íntimo, reconhecer seus erros, renunciar a seus desejos, como condição para a salvação e revelar seus segredos a partir das tecnologias pastorais de extração e produção de verdades. Força e potência são dadas a uma "alma" e o sofrimento é aplicado ao corpo como 
condição de salvação. O corpo vai sendo desvitalizado e a renúncia se processará pelo conhecimento de si.

Foucault (2008) assume que a Igreja, mesmo perdendo força desde o Século XVIII, expandiu-se para fora dos seus muros e constituiu novos agentes (Estado, polícia, família, hospitais, escolas etc.) para assegurar saúde, bem-estar e segurança, a partir de procedimentos normalizadores do exame e da "confissão".

\section{PROBLEMATIZANDO AS PRÁTICAS DE CUIDADO NA SAÚDE}

Nas minhas experiências na área da saúde, percebo que muitos profissionais de saúde operam a partir do discurso que, ao dizer "a verdade", a pessoa conhece a si mesma e torna-se conhecida para os outros, em um processo que é terapêutico. Isso me faz pensar nas conversas entre o profissional e a pessoa que chega demandando cuidado, operacionalizadas de forma interrogativa e regulativa, com perguntas dirigidas a fazer com que se produzam textos de identidade, ou seja, interprete "o que se é". Nesse sentido, o cuidado de si, na saúde, pode assumir uma posição de relação reflexiva da consciência de si, em outras palavras, a pessoa é levada a pensar como é ser ela mesma, em particular. Este domínio de si significa que a razão domina o corpo, e este continua como parte inferior.

São realizadas negociações técnicas que produzem precauções e prescrições de "estilos de vida". No campo da saúde, ainda existem muitas práticas de cuidado que obedecem a matriz de pensamento taxonômico, ativam processos de subjetivação com ideais de "estilo de vida", discutindo, ainda de forma modesta, o quanto a ideia de "estilos de vida" tem uma dimensão normalizadora, normativa, fundamentada na lógica da identidade e semelhança. Essa função de aplicador de taxonomias para discriminar indivíduos está presente desde as instituições de saúde às agências governamentais responsáveis em dizer o que ser, com o propósito de regular a distribuição dos direitos e as práticas de cuidado em saúde.

Pode-se notar que, em muitos conceitos formulados sobre saúde, há a noção de prolongar a vida, fazer viver. Segundo Foucault (1999), o fazer viver e o deixar morrer organiza-se como biopolítica a partir da discussão do poder sobre a vida: biopoder. Enquanto a estratégia disciplinar visava os corpos dos indivíduos, o biopoder (sem eliminar a disciplina, mas integrando-a) estabelece a preservação da vida da população. $O$ fato de viver passou a ocupar cada vez mais a cena do político, organizando-se a partir da lógica de tutela do Estado.

Esse poder se dirige ao homem espécie, aos processos de nascimento, morte, doença, baseados em estimativas estatísticas e medidas globais para estabelecer mecanismos reguladores da população, na busca da estatização do corpo biológico, criando normas de como se deve viver e de que meios de vida são desejáveis. Assim, a vida é gerida, regulada, administrada, controlada para funcionar segundo um padrão ideal. 
Dentro desse contexto, segundo Foucault (1999), a saúde é cultuada como interligada à vida e como valor supremo, e a morte é progressivamente desvalorizada, pois o morrer extrapola o controle desse poder de fazer viver. Percebe-se que desse modo, há um crescimento do mercado de produtos com promessas de alcance desse padrão ideal de saúde, para não correr o risco de adoecer. Constrói-se um saber que empurra a saúde para o consumo excessivo de bens, serviços e terapêuticas medicamentosas e busca-se medicalizar modos de vida que são tidos como ameaçadores desse padrão de saúde.

Patologizam-se modos de viver e implantam-se estratégias de controle e regulação sobre o cuidar de si, com produtos que não só garantem o estabelecimento de uma saúde fisiológica, mas também, melhores condutas e melhores estados emocionais. O corpo é um objeto de incidência desses saberes e dessas estratégias de poder. Há uma exclusão e punição aos que resistem (chamados de resistentes) a essas normas e ousam experimentar a corporalidade fora das medidas regulamentadas.

O biopoder se exerce no nível não só da espécie, mas também da raça. Ao falar sobre racismo, Foucault (1999: 308) diz que esse é o responsável pelo "corte entre o que deve viver e o que deve morrer", separando os grupos entre os que podem ter sua vida ampliada e um subgrupo descartável. Para Deleuze e Guattari (1996), o racismo, em função do padrão Homem branco, pretende integrar os traços que não são conformes, incriminando os que não são e propagando as ondas do mesmo até à extinção daquilo que não se deixa identificar.

De acordo com Cloos (2015), a Saúde Pública implementa ações de racialização, quando funciona dividindo a população em relação aos corpos, situando e opondo os grupos racializados (através de rótulos inventados desde o regime colonial) aos grupos que representam a brancura como padrão e símbolo sanitário.

Ao conversar com os profissionais de saúde de Monsenhor Tabosa em 2016 que estão no município há aproximadamente 2-3 anos, alguns, morando nessa localidade, mas sendo naturais de localidades vizinhas e possuindo experiências na Atenção Primária -, escutei que os trabalhos que desenvolvem, comparados aos das unidades de saúde não-indígenas, não apresentavam muitas diferenças.

O Distrito Sanitário Especial Indígena, no Ceará (DSEI-CE), com sede em Fortaleza, está estruturado em 9 Polos-base, 18 municípios, 21 equipes compostas por médico, enfermeiro, dentista, técnico de enfermagem, auxiliar de saúde bucal, agentes comunitários de saúde indígena (ACSI) e agente indígena de saneamento (AISAN), com atribuições semelhantes às Equipes da Estratégia Saúde da Família (EqSF), mas com a tarefa específica de atuar em aldeias indígenas.

As maiores dificuldades que apontaram foram a falta de estrutura (às vezes, não havia maca nos espaços para realizarem prevenção ginecológica) e a relação demanda espontânea e o cumprimento de metas exigidas pelo governo. 
Expuseram que por falta de vontade ou devido às longas distâncias, havia pouca busca dos indígenas por algumas ações em saúde como prevenção ginecológica e vacinação, assim, ocorria um comprometimento das metas que aos profissionais eram impostas. Porém eles não problematizavam essas metas nem a situação de pressão a que eram expostos nem a convocação para gerenciar um "milagre" - termo que apareceu em algumas falas dos profissionais - que é atender complexas e múltiplas necessidades através de recursos escassos.

Outras dificuldades, como a falta de exames, a demora nos resultados, a falta de ambiência - pois havia locais em que eram realizadas as prevenções, que permitiam ver o que acontecia no recinto em que era feito o procedimento -, que escutei de mulheres indígenas, não eram analisadas, pelos profissionais, como favorecendo a decisão pela não procura da prevenção ginecológica nos serviços públicos de saúde por parte das mulheres indígenas.

Os profissionais afirmavam que a distância e a quantidade de aldeias impossibilitavam 2 ou mais visitas por mês em cada localidade. O problema não era a quantidade de equipes, mas questões geográficas e o quantitativo de aldeias, assim, problematizavam situações que não poderiam modificar e não questões que os levassem a fazer uma análise do sistema de saúde e os tornassem responsáveis pela transformação. Acrescentaram que estavam esperando a construção de um polo de atendimento, mas sabiam que, mesmo com uma estrutura para alguns tipos de consulta, as visitas precisariam continuar e a equipe "torna-se itinerante", pois algumas aldeias ainda continuariam distantes da unidade de saúde.

Disseram que os indígenas tinham dificuldades para aceitar as vacinas e para procurar os profissionais de saúde. Acreditavam que muitos só buscavam as unidades quando se sentiam doentes, e que por isso não pensam na prevenção das doenças. Lembrei-me de uma conversa sobre vacinação com as lideranças indígenas, em 2015, em uma universidade do Ceará, na qual uma das pesquisadoras indígenas disse:

Nós somos tão nômades, nunca vão compreender isso aí. Eles chegaram com a lista do povo para vacinar e nós já estávamos em outro canto. Aí dissemos "Ou você vacina todo mundo ou você vai embora com sua vacina, pois se é para proteger, tem que proteger todos. Como você não pode acreditar que essa menina é a de Pedro? Se vocês não acreditam em nós como vamos acreditar em vocês?”.

A lista a que se referem é a de meta das vacinas, e o nomadismo aqui não se reduz a um movimento entre espaços físicos, mas movimentos pelos quais a nossa lógica de pensar a vacinação é deslocada. Enquanto, em um momento, a recusa da vacinação é vista pelos profissionais como sendo descuido por parte dos indígenas e, em outro, ela é estimulada para não ultrapassar as metas, os Potyguara dizem de uma vacinação percebida como proteção e cuidado, logo, deve ser direcionado para o coletivo e não algo restrito a uma lista de pessoas. 
Os profissionais diziam que não possuíam tempo para cuidarem de si e que se sentiam pressionados pelas exigências feitas pelos indígenas, que, muitas vezes, possuíam uma postura de acomodação e espera, o que tornava a equipe obrigatoriamente responsável pelo cuidado em saúde, e o processo de responsabilização como uma invasão controladora da vida do usuário. Por outro lado, afirmavam que o trabalho no território indígena os havia aproximados da utilização de uma alimentação natural, usos de chás e de crenças nas rezas e nas doenças como mau-olhado.

Nas práticas de saúde do sistema formal, percebe-se, em muitos casos que, na relação profissional-usuário, cria-se nas pessoas, que demandam atendimentos, a partir de uma infantilização, dependência, impotência, fraqueza, uma vontade em serem cuidados que mascara a intenção dos profissionais de saúde em garantir suas profissões de cuidadores. Desse modo, invisibiliza a vontade dos que cuidam pela fabricação de uma vontade daquele que é cuidado.

Institucionalizamos o cuidado em saúde, ditando regras para dizer quem precisa de cuidado e como deve ser o cuidado em saúde. Assim, nosso cuidado torna-se mais uma moral pela qual submetemos os outros às formas de cuidado que imaginamos que eles têm que receber. E, desse modo, criamos dependências, já que nós colocamos como detentores das regras de como viver bem.

Produzem-se relações de cuidado que elencam um modo de vida saudável e desejável, operando pela via da moral em detrimento das forças que fogem ao já capturado. A escuta dita qualificada é canalizada para ouvir sintomas, erros, incoerências com o modelo correto de ser saudável para então se elaborar um plano de cuidado que mais parece um guia de correção, de catequese.

O termo "integralidade", na área da saúde, é tido como um avanço. Porém, essa cultura de integração, que parece hoje constituir regime enunciativo e prático hegemônico, apresenta-se com a incorporação da lógica biomédica aos cuidados tradicionais. Raramente se questiona os padrões que se tornam norma e sobre as normas que levam à desqualificação de outros modos de saber e produção de cuidado.

A integralidade aparece como travestida de cuidado, porém, muitas vezes, acoberta um campo de iniquidades e colonizações em saúde, que não extingue as diferenças, mas as incorpora segundo ajustes toleráveis aos padrões que funcionam como centros de referência e de poder. É o que percebemos com a inclusão das "ervas do mato", como plantas medicinais, atualmente, artigos vendáveis por várias empresas de produtos naturais.

A configuração ampliada da Clínica, segundo Campos (2003), desloca o cuidado da doença para o sujeito, incluindo o seu contexto, com suas formas de adoecimento e com suas formas de criar processos denominados de saudáveis. Porém, esta Clínica Ampliada apresenta-se como um desafio, pois se configura dentro de um espaço marcado pela soberania do olhar do profissional sobre a saúde. Esse olhar é atravessado pela instrumentalização e enriquecido por descobertas fruto de observações quantitativas ou qualitativas, mas dentro de uma lógica baseada em frequências. 
O adoecimento é trabalhado a partir de um modo controlado, normativo de gerenciamento e controle. Olha-se para o adoecimento como processo de patologização do corpo.

Foucault (2011) versa sobre o nascimento do saber médico e da clínica do século XVII ao final do século XIX, refutando a ideia, historicamente construída, de que a medicina surgiu pela aproximação do médico ao leito do doente. No século XIX, o olho médico se volta para ver o mal se expor e se dispor diante dele à medida que penetra no corpo. Logo, o movimento não é de aproximação entre o médico e o doente, mas entre o saber médico e a doença na profundidade do corpo. E todo esse olhar parece percorrido por uma necessidade classificatória, seja através de um quadro, sintomas, ou, através de um corpo, seja através de analogias, variações qualitativas, frequências e/ou alterações visíveis que o estado de doença produz nos órgãos do corpo humano.

A nova experiência clínica se arma do olhar que se volta somente para o que é visível, evidente. $\mathrm{O}$ corpo é reduzido ao organismo, local onde a saúde instala seu arsenal de poder. Nestes espaços institucionalizados, o sujeito aparece como ocupado em se descobrir, controlar-se, recuperar-se, havendo escassos lugares para produção e criação.

\section{A VIDA COMO PRODUÇÃo DE SAÚdE PARA OS INDÍGENAS POTYGUARA}

Os Potyguara afirmam, pela produção da vida, que as forças extrapolam o domínio do perceptível e recusam, muitas vezes, ver coisas que nós consideramos como evidentes. É possível ver o que não é visível! As coisas não se esgotam no que é visto, ou no que dizem do que é visto e, pelos rituais de cura, operam outros modos de visibilidade.

O corpo e a voz são elementos importantes nos rituais. O corpo, aqui, não se restringe ao organismo e nem à origem das necessidades e dos prazeres. Os corpos se compõem de danças e rituais de cura. Estes rituais conectam elementos heterogêneos cristãos, ameríndios, africanos, vozes, olhares, gestos e rezas.

Em datas importantes para os Potyguara, as comemorações são iniciadas por rituais que acontecem em lugares tidos por sagrados, como debaixo de árvores ou nas escolas, considerados espaços nos processos de luta política. A presença dos professores indígenas e dos alunos opera um estímulo à participação nos rituais, e a qualificação dos professores indígenas é percebida pelos Potyguara como aumento da força política para as lutas a fim de garantirem seus direitos.

A respeito do Toré, Palitot e Albuquerque (2002: 145) expõem:

O lúdico predomina, mas mesmo assim, ousaria dizer que seja a forma por onde se expressam os conteúdos étnicos, políticos e religiosos do grupo, sem que para isso haja uma formalização excessiva. 
Dito de outra maneira, pelos rituais também se brinca e brincando faz-se política, trabalha-se a espiritualidade, criam-se sociabilidades e conhecimentos, produz-se vida, criam-se processos saudáveis.

Através do olhar do xamã, com os modos que ultrapassam o ver e o evidente, produzem ligações que os conectam com animais, com vegetais e com coisas e com espíritos. Através das relações entre danças e cantos e rezas e pinturas e artefatos e gritos se produz vida e saúde. As danças, os cantos, as rezas são produções que desestabilizam as compreensões que temos de saúde, cuidado e política.

Política é vida! Mas não dentro da lógica capitalística de que tudo é vida, tudo é saúde, tudo é de interesse político, logo de responsabilidade do Estado, agência reguladora e de controle. A busca de direitos pelos indígenas são condições não de um retorno ao sujeito como instância dotada de deveres, mas produção do viver.

O cuidado do doente pelos indígenas, nas figuras dos curandeiros, já estava presente antes da chegada do europeu, sendo assim, o indígena, a partir de diferentes grupos, possui maneiras de intervir no cuidado. Um cuidado entre dois, entre vários, intersecções pelas quais é preciso viver a vida, não apenas sobreviver.

A saúde Potyguara é um convite a trabalhar artisticamente com o sofrimento. Não se trata de ocultá-lo, mas libertá-lo, libertação da dor pela dança, pelo canto, pelas rezas, pelos rituais, pelas brincadeiras, pela plantação e colheita, pelo riso, pelo choro, intensificando as forças de vida.

O adoecimento, que quebra a sequência e instaura um acontecimento, encontra na saúde uma abertura para vitalização. É uma saúde como afirmação de uma inseparabilidade das dores que o corpo expressa. O adoecimento é uma experimentação do corpo e da vida.

O cuidado em saúde não surge do dizer 'eu devo cuidar de você'. Não é uma obrigação, um dever, mas agir do viver em comunidade. A morte é vivenciada a todo instante da vida, e nesse entre é possível criar. Ela é acompanhada pelos Potyguara de rituais de choro e com comidas, podendo ser avisada pelo cantar dos galos fora do horário.

A produção de vida Potyguara traz a saúde como sendo engendrada pelos encontros (não apenas humanos e orgânicos). Os Potyguara são minorias que não se adequam aos padrões normativos de saúde, de vida e trazem novas formas de viver e agir, de produzir vida. Percebe-se que não é a saúde que é tida como valor supremo, mas a vida. A possibilidade de viver e criar é que diz da saúde nesses povos.

Em um dos encontros do grupo de pesquisa sobre saúde indígena, enquanto se discutia sobre os artigos publicados sobre a temática nas revistas de Saúde Coletiva, uma professora visitante perguntou à liderança indígena sobre o que seria saúde, ao que ela respondeu "ausência de doença, é também genética...", sendo logo interrompida com outra interrogação da docente: “genética?!”. 
Surpresa diante da admiração interrogativa da professora, a liderança indígena disse embraçada: "sim, quando a doença do pai passa pro filho", sem ir mais adiante nessa explicação, entrou em outro fluxo e disse "saúde pra nós é plantar, colher, viver bem com a comunidade”.

Na conversa com os Potyguara, a saúde está em relação com o plantar, colher, viver bem com a comunidade, com a terra. A questão da terra é algo que está conectado com a moradia, relações familiares, alimentação, educação, com a saúde, ou seja, com a vida, reverberando do e no corpo.

Falar dos modos de vida dos Potyguara não é buscar um tratamento, pois muitas vezes, esse tratamento está em silenciar a potência de vida, tirar os entrelaçamentos entre adoecimento e saúde, agenciar formas higienizadas, que exclui outras produções do vivido.

Percebe-se novas estéticas da relação entre saúde e vida, políticas cosmológicas corporais através das quais são criadas novas possibilidades de existência que operam desestabilizando sistemas higienistas, biopolíticos de normalização e controle da vida, além de um corpo como instância inferior a alma e apartada do pensamento e do mundo.

Foucault (1989) nos oferece uma compreensão de resistências, a partir dos corpos, pois é por esses corpos que se manifestam os efeitos do poder, e que também são territórios de resistência, e para Deleuze (1992), a resistência acontece pela irrupção do novo, do "pensamento nômade".

Ao pensamento nômade não interessam as partidas ou chegadas, mas os percursos de criação, de ruptura com as situações vigentes, de desvios dos códigos universais. Desse modo, o pensamento nômade Potyguara institui-se por seu combate contra o ideal de saúde indígena. Ele insurge-se para afirmar modos de saúde singulares que rompem com os valores estabelecidos, propondo a criação de valores que afirmem modos de vida ativos.

Os Potyguara são resistentes do presente e fazem de suas vidas, de suas relações, um campo de experiências de resistência, de criação, de deslocamentos contra as formas de captura normalizadora.

\section{CONCLUSÕES}

Os modos de produção de vida Potyguara podem operar deslocamentos na saúde, no cuidado e na clínica na área da Saúde Coletiva. Levantar da cadeira dos consultórios, onde se repete o mesmo dos guias, manuais e políticas, e seguir os fluxos de intensidades e afetações da produção de vida Potyguara, que afirmam a diferença, caminhando em estilizações da vida nas quais a saúde não está pronta, estruturada, mas em processo ininterrupto de criação.

A clínica e o cuidado em saúde podem aprender com esta produção de vida a caminhar, deslocar-se e mapear novas rotas, percebendo como as virtualidades se atualizam em atos-com.

Entre a Saúde Potyguara e a Saúde Indígena as intensidades vibram e não está em questão descrever atributos a priori, universais, essenciais de saúde, mas 
pontos de ultrapassagem e problematizações das práticas de subjetivação da saúde indígena, a partir dos processos de singularização dos Potyguara que assumem a vida como produção de saúde.

\section{REFERÊNCIAS BIBLIOGRÁFICAS}

CAMPOS, Gastão Wagner Sousa. Saúde Paidéia. São Paulo: Hucitec, 2003.

CLOOS, Patrick. Pouvoirs, Différence et Stéréotypes : Regard SocioAnthropologique sur la Santé Publique Américaine. Québec:Presses de l’UniversitéLaval, 2015.

DELEUZE, Gilles. Conversações. Rio de Janeiro: Editora 34, 1992. 232 p.

DELEUZE, Gilles; GUATTARI, Félix. Mil Platôs:Capitalismo e esquizofrenia vol. 3. Tradução de Aurélio Guerra Neto et alli. Rio de Janeiro: Editora 34, 1996.

FOUCAUlT, Michel. A Hermenêutica do sujeito. São Paulo: Martins Fontes, 2006. . Em defesa da sociedade. São Paulo: Martins Fontes, 1999.

. Microfísica do poder. 8. ed. Rio de Janeiro: Edições Graal, 1989.

2011.

. Nascimento da Clínica. 7 ed. Rio de Janeiro: Forense Universitária, . Segurança, Território, População. São Paulo: Martins Fontes, 2008.

INSTITUTO BRASILEIRO DE GEOGRAFIA E ESTATÍSTICA. Estimativa de população série 2001-2016. 2016. Disponível em IBGE (ftp://ftp.ibge.gov.br/Estimativas_de_Populacao/Estimativas_2016/serie_200 1_2016_TCU.pdf). Acesso em 10/12/2017.

PALITOT, Estevão Martins; ALBUQUERQUE, Marcos Alexandre dos Santos. Relatório de viagem: Índios do Nordeste (AL, PE e PB). Campina Grande: LACED; UFRJ, 2002. Disponível em Laced (http://laced.etc.br/site/pdfs/Indios_Nordeste.pdf). Acesso em 20/o2/2016. 